\title{
INTERNAL CONSISTENCIES: REGARDING WEIGHTS AND MEASURES
}

\section{ELIZABETH SHOTTON}

School of Architecture, Landscape and Civil Engineering

University College Dublin

Richview Campus, Clonskeagh, Dublin 14, Ireland

elizabeth.shotton@ucd.ie

\begin{abstract}
Rather than seeing a distinction between theoretical discourse and the science of building Vitruvius, a Roman architect and engineer active in the 1st century $\mathrm{BC}$, argued convincingly for the breadth of knowledge necessary to practice architecture with authority, that "knowledge is the child of practice and theory". The crux of his argument is that a sufficient breadth of training, to appreciate both the theoretical and practical sciences, is necessary to lend authority to creative vision.

In like spirit, a series of workshops in UCD Architecture has sought to challenge the contemporary lack of sympathy between theoretical discourse and the science of building which disables the authority with which both students and practitioners practice. Embedded within each workshop are variations regarding intent, from the cultural discourse of the international collaboration of the North Atlantic Rim project, to the theoretical concerns of the Ateliers Series and environmental bias of the Irish Timber course, each drawing upon discourses external to architecture and leavening them against the inherent logic of material and structural imperatives. The resulting evolution in design process, linking both technological imperatives and conceptual intentions to the creative act, shatters the prevailing disjunction between theoretical concerns and technological explorations in the discipline of architecture.
\end{abstract}

Keywords: Technology, Material Practice, Design Build, Education.

\section{Introduction}

1. THE architect should be equipped with knowledge of many branches of study and varied kinds of learning, for it is by his judgement that all work done by the other arts is put to test. This knowledge is the child of practice and theory. Practice is the continuous and regular exercise of employment where manual work is done with any necessary material according to the design of a drawing. Theory, on the other hand, is the ability to demonstrate and explain the productions of dexterity on the principles of proportion.

2. It follows, therefore, that architects who have aimed at acquiring manual skill without scholarship have never been able to reach a position of authority to correspond to their pains, while those who relied only upon theories and scholarship were obviously hunting the shadow, not the substance. But those who have a thorough knowledge of both, like men amed at all points, have the sooner attained their object and carried authority with them.

Vitruvius Pollio, The Ten Books On Architecture, Chapter I: The Education Of The Architect 
The transfer of knowledge into the discipline of architecture is not a new phenomenon, although the rapidity of transfer and complexity of information on offer exceed historical trends. The validity of this transfer should be understood within this context, that architecture, by its very nature as a social, political and material art, necessarily demands a wide spectrum of knowledge on the part of its practitioners to achieve work both functional and meaningful, as so aptly argued by Vitruvius. Rather than a lack of sympathy between theoretical discourse and the science of building, Vitruvius appreciated the breadth of knowledge necessary to practice architecture with authority, that "knowledge is the child of practice and theory" [Vitruvius 1].

Contemporary debate should lie not in the validity of the transfer but rather its synthesis with the more specific and technical aspects of the discipline. In a recent publication on material based practice argues that architectural practice and the discourse surrounding it have historically and principally been form based, eschewing material resonance, and it is within these discourses that alternative fields of endeavor have had their influence on architecture [Lloyd Thomas, 2]. The implicit difficulty in this history, and its radical difference to the attitude expressed by Vitruvius in the first century $\mathrm{BC}$, is the tension implied between form and its resolution as material artifact. Severing broader frames of reference from material realization creates a disjunction between critical imagination and the material constraints of building, disabling the authority with which architecture is practiced. As Lloyd Thomas argues in Material Matters, the potential of reversing this predisposition, to focus on material realities not as servant to form but as inspiration, can open up equally broad fields of inquiry; economics, environment, social custom and material production [2], describing a similar field of knowledge implicated in formal concerns yet from a significantly different perspective.

Doubt lingers within Lloyd Thomas' essay as to whether this shift in priorities repairs the oppositional character of formal conception and the material realities of building. A series of workshops developed within the Architecture Programme at University College Dublin has sought to encourage just such a shift in thinking and making, with results which imply that this oppositional condition can be leveled, that the generous image of a marriage between theory and the practical bequeathed to us by Vitruvius is indeed possible and still relevant within a far more complex world and profession.

\section{Thesis Research and Les Grands Ateliers}

Strategies to reconcile technical imperatives with theoretical discourse vested in the current Ateliers programme have a lineage from the AA with the Weather Register [Salter, 9], which focused on the elements of nature and landscape, and the Technical Study, intended to "test and reinforce the instinct behind the strategy" as Salter describes [14]. Adopted into the programme at UBC in Canada and later evolving into Constructed Order, a studio intent on instilling a similar intuition regarding materiality, it became apparent that these ideas, whether environmental or material, when introduced into design education at an early stage, became foundational to future work as a form of intuitive knowledge [Lui et al, 114] effectively linking imagination, conceptualization and making.

In contrast contemporary architectural discourse tends to understand building form in representational terms, which renders its materiality invisible [Lloyd Thomas, 7], aptly describing the prevailing ideology at the School of Architecture in Dublin, which eschews the compelling forces of materiality and environment for a more intellectualized attitude. Theoretical discourse typically has a generative impact but in a manner that is representational and static, failing to accommodate material and structural imperatives [Allen, xxv]. Set the task of revising this predisposition at thesis level, the principles gleaned from earlier work undertaken were adopted, leading to the evolution of workshop programmes intended to test theoretical polemics against the resistance of material, structural, environmental and economic issues.

Originally held at UCD, experiments were undertaken at model scale, which, while useful, remained within the realm of representation and reinforced the prevailing formalist attitude [Shotton, 164]. Significant to the evaluation of this programme were studies on cognitive learning and modeling by Parkinson, indicating that there is a differential in learning across different scales and types of representation. While all forms of modeling are useful to the development of imagination, modeling that reached a scale where 'engineering' concerns became relevant in addition to shape making, creating more strenuous experimental conditions, were more salient in the process of hypothesis creation and testing [Parkinson, 14]. Scale of experimentation then is central, as was to be corroborated with the experience of the programme as it developed into full-scale studies. 


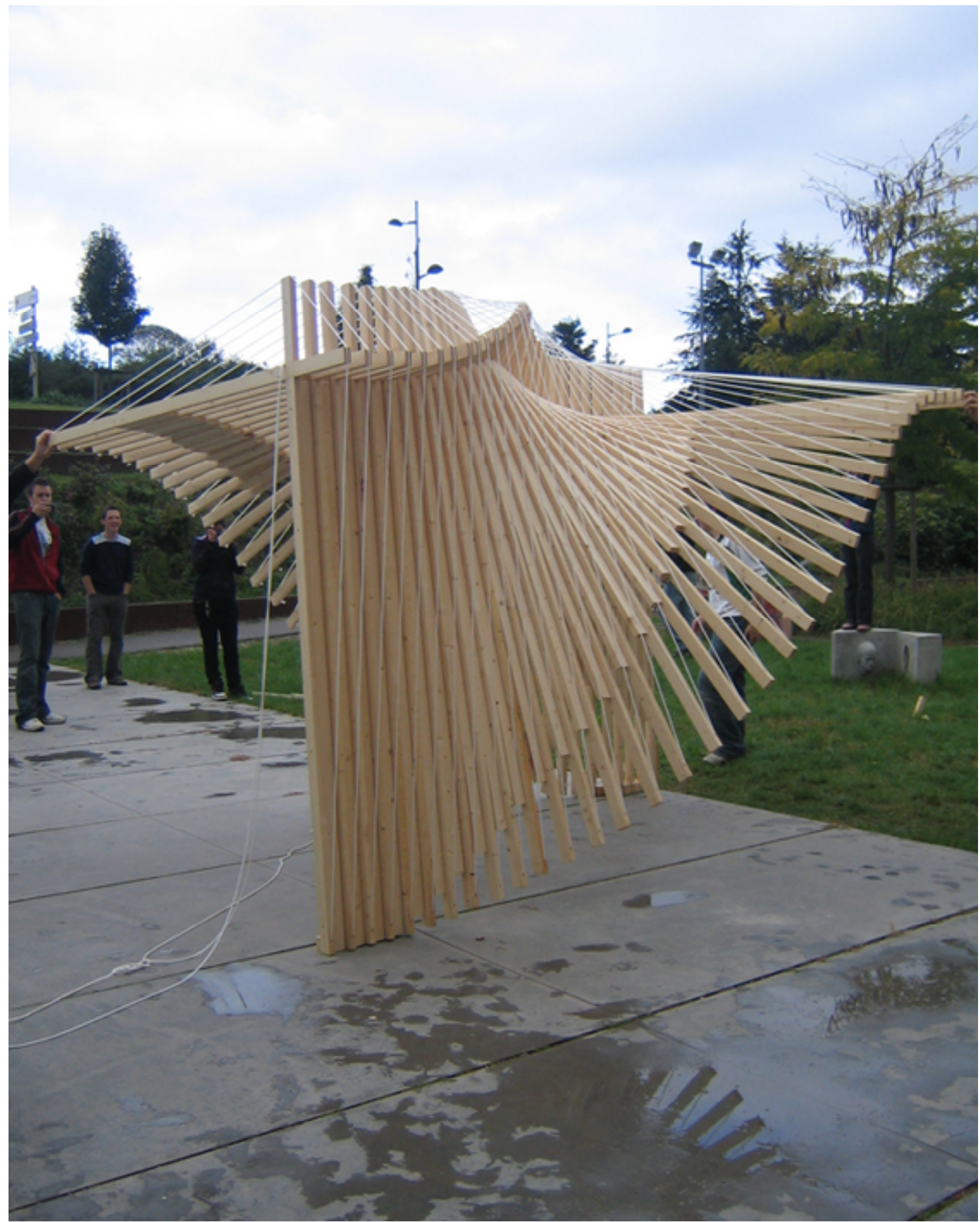

Image 1: Les Grands Ateliers Workshop 2006 Students: Jacinta Curley, Gordon Chrystal, Dierdre Keeley, Lucy O'Connor, Sandra Sibley, Padraic Ward

Relocated to a venue that could house 1:1 experiments enabled students to confront 'engineering' concerns in the form of actual materials and structures, to encourage hypothesis testing and transformation. Critical to the organization of this five-day exercise is the arrangement of students in teams, significant as it necessitates the negotiation of individual concerns into a mutually relevant premise. Equally important was the elusive character of the brief suggested; wall, chair, roof; evocative yet intentionally broad to allow for interpretation in terms hypothesis, form and material use. Initially structured as a sequence of drawing to building, this process again exposed the formalist predispositions as drawing studies bore no technical insights and were rapidly discarded once building was undertaken. Altered to a more promising structure in which material is engaged with immediately enabled the shape, texture and inherent properties of the physical to influence both negotiated position and resultant form [Image 1]. Working directly with material brought theoretical, social and political concerns, more commonly attributed to 
form generation, into direct confrontation with material and technological imperatives, allowing both to contribute to the conceptual positioning of the project.

Equally constraints aided investigations, for while the work from the first year was experimental and visually engaging due to risks taken in material choices and in the interpretation of the brief; ranging from a multi-tiered 'breathing wall' constructed exclusively of OSB and housing up to nine people simultaneously to a red lycra scrim which flexed interactively with the Atelier's folding door system; the provisional character of the constructions suggested a different approach was required. While the influence on the formulation of thesis was significant enough to infiltrate later design studies, the form of influence was on the level of metaphor, importing conceptual and formal ideas to later experiments yet failing to advance material instinct except in a few rare cases.

In response material was restricted to timber, to challenge construction skills more directly, while allowing the brief to remain elusive. However the form of brief was equally critical to the success of the later adaptation of knowledge as was to become clear. The second brief undertaken was the 'chair', the form and placement of which could act as a measure of space and thus could be understood as a primal form of architecture. The intimate nature of the object and restricted material palette proved a test of construction skill and elicited in later work a greater concern for the intimacy of material and implications of process. Yet the object like character of the constructions failed to engage spatial concerns, thus the intuitive knowledge later applied was limited to detail rather than influencing form.

Most successful was the 'roof' project, carrying with it implications of space, form, structure and material. The work undertaken, ranging from studies in adaptable systems building to experiments in "thick space", were less engaging as visual objects yet had profound influence of the work that was to emerge later in the year. The translation is by no means direct, but rather have engendered more synthetic resolutions of competing discourses where design studies, previously form driven, now explore attributes of form, structural resolve, tectonic expression and theoretical concern simultaneously.

These experiments have confirmed the hypothesis regarding the subliminal influence early material experiments have on the design process. Significantly though this phenomenon is influenced to a large degree by the scale of engagement, the complexity of the brief while lessons learned seem transferable across material. Crucial however is the simultaneous negotiation of material, form and conceptual premise in influencing intuition.

\section{North Atlantic Rim Research Collaborative}

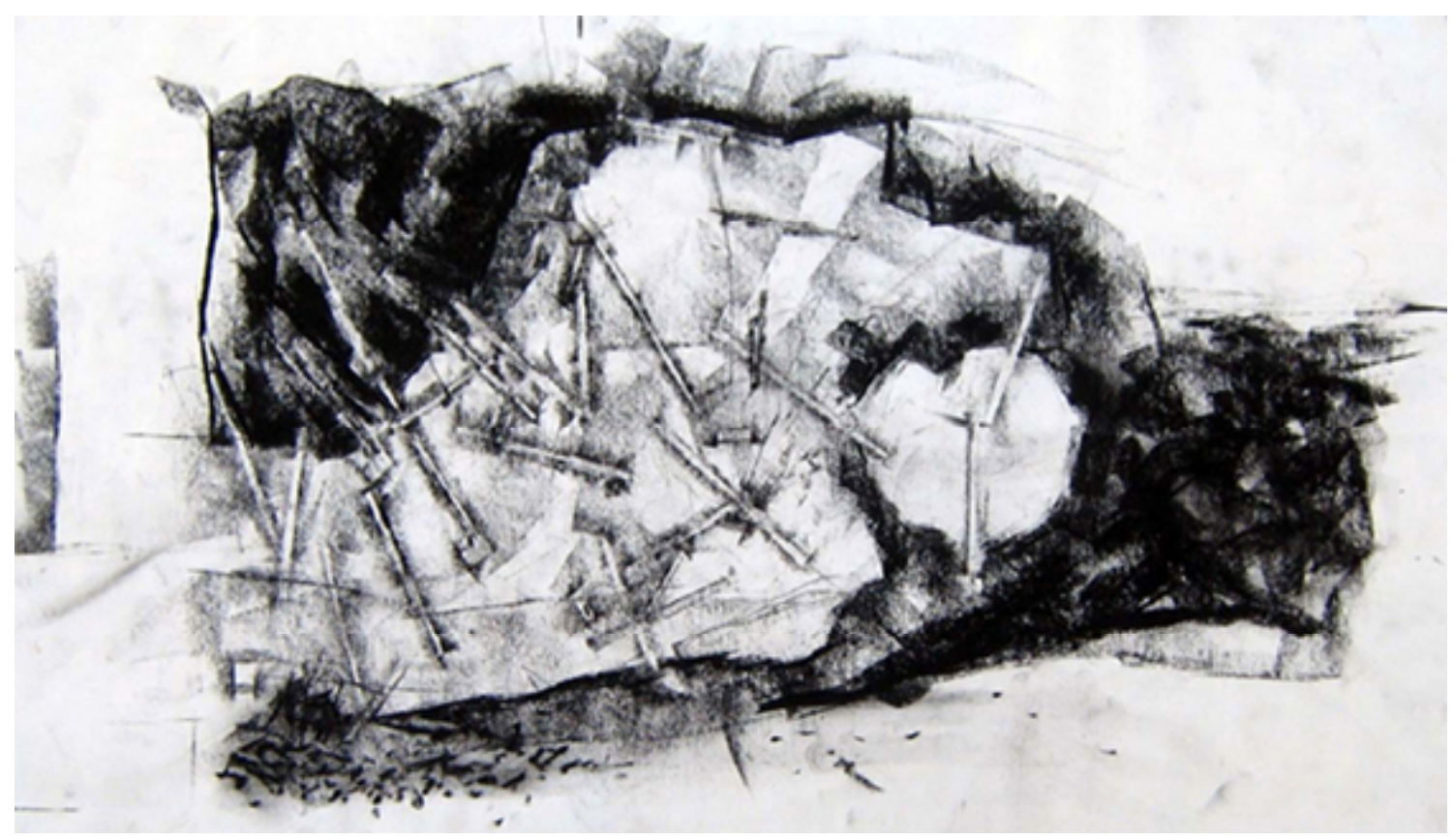

Image 2: Cheticamp, Nova Scotia Site Drawing, NAR 2006, Roger Mullin 
Drawing, as intermediary between creative thought and building process, is a critical tool for both investigative and communicative purposes and was used as the principal medium by NAR, an international research collaborative initiated in 2004 , to identify salient aspects of landscape that inform culture, building and settlement patterns. Orthographic representation to translate experienced realities to measurable and comparable data enabled close examinations of the landscapes and buildings through measure, proportion, scale and materiality - with the emphasis on the underlying materiality of the land - that informed the secondary layers of the built. These studies culminated in 2006 with a design build project in Cheticamp, Nova Scotia, which was intended to transform this knowledge from perception to imagination and finally making.

Resolution to the contested territory of local school, summer theatre camp and retirement home was initially studied in model and drawing across three groups of students. Evident was a lack of regard for the constraints a two-week building project implied - material, technical, economic or process based - with notable exceptions among the students who had participated in the earlier drawing studies. Amongst these was a lingering attention to the natural features of the landscape and references back to construction typologies observed earlier. Nevertheless, when reviewed as a set of alternatives it became clear that pre-conceived formal agendas, inattentive to the specificity of physical constraints, prevailed. A shift in process was clearly needed to enable a more holistic solution to the difficult physical and social terrain to be negotiated.

Scott Poole, in his assessment of design processes among his own students, has suggested that "...simulation of mental images detached from the veracity of matter and the means of production can have an illusory effect on the imagination and foster constructive naiveté. [111]. Yet it is not simply digital media, to which he refers, which suspends realities in form making. Rather it is the over dependency on abstract representations which so often precludes a more intimate reading and authoritative translation of a context. Tactile engagement is a principle means of perception and thus critical to learning and invention, as Parkinson's research has suggested. Deprived of this experience visual imagination remains uninformed as to the weight and measure of reality. Addressing this issue meant developing a more precise structure to link tactile engagement, perception and imaginative processes.

As a means of measuring both site and building material, consisting of heavy timbers, rebar and plywood restricted in quantity by issues of budget, students and staff engaged in a form of $1: 1$ on site sketching, distributing the material across the site in response to sequences of instructions to articulate gathering places, solitary places and spaces of movement. From this position material was subtracted in a similar process to assess the potential of the site against the measure of the body and scale of the material. The outcome was a far more sophisticated reading of the site, both physical and social, than any achieved through earlier modeling. While initial representation in plan [Image 2] bore no recognizable form, when built a complex network of social spaces which negotiated a difficult terrain [Image 3] using a simple but sophisticated language of pin connections, with timber and rebar, inspired by local heavy timber wharf constructions resulted. Speculation, on a physical and collective level, combined with the urgent pressures of construction enabled the earlier landscape studies, so carefully absorbed through slow documentation, to surface in an imaginative and unexpected manner through an recasting of material, technology and cultural history.

Similar to the Ateliers project, engagement with material enabled a form of learning and invention to occur which was more comprehensive in its management of theoretical aspirations, societal concerns and material realities. The differences were equally significant however. While the use of prototypes in short design studies enables students to recognize the potential marriage between theoretical concerns and construction it can fail to open up the broader discourse implicit within materials and their assemblage into form, from the economic to the cultural or the regulatory, which influence the outcome of a project, such as at Cheticamp, and which are too easily overlooked in the controlled environment of the studio. 


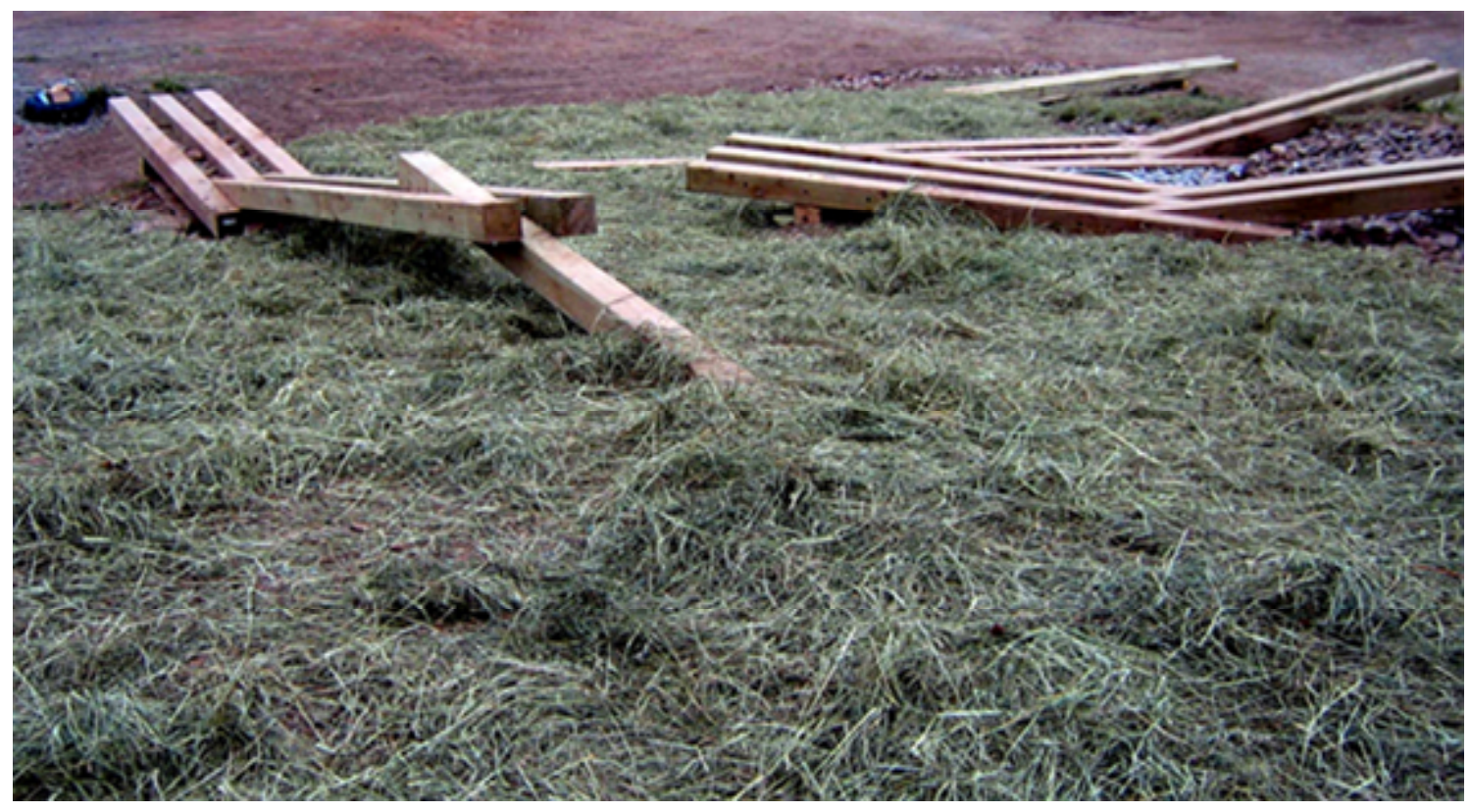

Image 3: Cheticamp, Nova Scotia Construction, NAR 2006

\section{Irish Timber \& Sustainability}

Shifting attention from the formal to the material in design practice should not imply the loss of a broader discourse and intelligence being brought to bear on the creative process. Suspending our culturally insinuated predisposition to limit material relevance to the aesthetic and the techniques of assemblage opens a vast network of associated fields embroiled in the building materials with which we negotiate. Contemporary issues of environmental degradation, for instance, have forced the global community to recognize the weight of issues that factor in the production, use and reuse of materials. Unfortunately too many advocates of sustainable building practice reduce its potential through generalized principles which, when applied to specific regional contexts, undermine the basic intelligence of the proposition. Application in too generalized a fashion within Ireland has encouraged an expanded use of timber construction, inherently contradictory in a country where the quantity, quality and diversity of timbers available locally is limited leading to the importation of material, carrying with it significant embodied energy costs. A more positive scenario would be to use local timber more effectively in construction, and consider the species currently under cultivation as a long-term strategy.

A recent course at UCD aims to counter this simplified premise through examination of local timber resources across a range of interdependent issues such as historic changes to forestry, the associated ecological, social and economic causes and effects to more specific issues such as the appearance and workability of types of timber. Serving as a foundation for individual student research these lectures also inform the 1:1 collective design/build investigations undertaken by the class to enrich their attitudes toward material use relative to design intentions. The intention is that each subsequent session would focus on different potential applications and alternative construction typologies through the medium of the design build project. In 2007 the indigenous and exotic species currently under cultivation in Ireland was researched, underpinned by lectures in historic trends in woodland development and depletion on the island, contemporary silviculture and forestry management techniques, issues of biodiversity, and properties locally available timbers. These discussions alone raised awareness as to the complexity of economic, environmental, regulatory and cultural issues influencing the management and distribution of timber resources, the implications of which were underlined in the design build projects which followed.

Sitka Spruce, an exotic in Ireland, is the principal species currently under cultivation due to its accelerated growth pattern thus making it the ideal candidate for this initial project. The disparity manifest between the stocks of lumber supplied to the project was sufficient lesson in and of itself regarding the implications of sourcing locally. Irish spruce is significantly more porous and flawed due to both provenance and growing conditions, lowering its structural properties significantly. The scale of available timber was also limited resulting, for this project, in the importation of Baltic spruce which proved both 
larger, more materially stable and structurally reliable. Though one can describe in classroom settings the quality and scale differential between imported and locally grown spruce, in this setting, where choices having significant consequences on form, detailing and the sheer workability these differences became compelling.

The peculiar artifacts, which occupy the college green, are welcome additions that sponsor continual occupation. Equally, the traditional wood joinery used serves its own educational purpose [Image 4]. But the critical knowledge acquired in this course was the breadth and complexity of issues raised when one examines any building material closely, expanding an awareness well beyond notional ideas concerning appearance, material properties or assembly to encompass the social and cultural constructs so often associated with more formalist concerns.

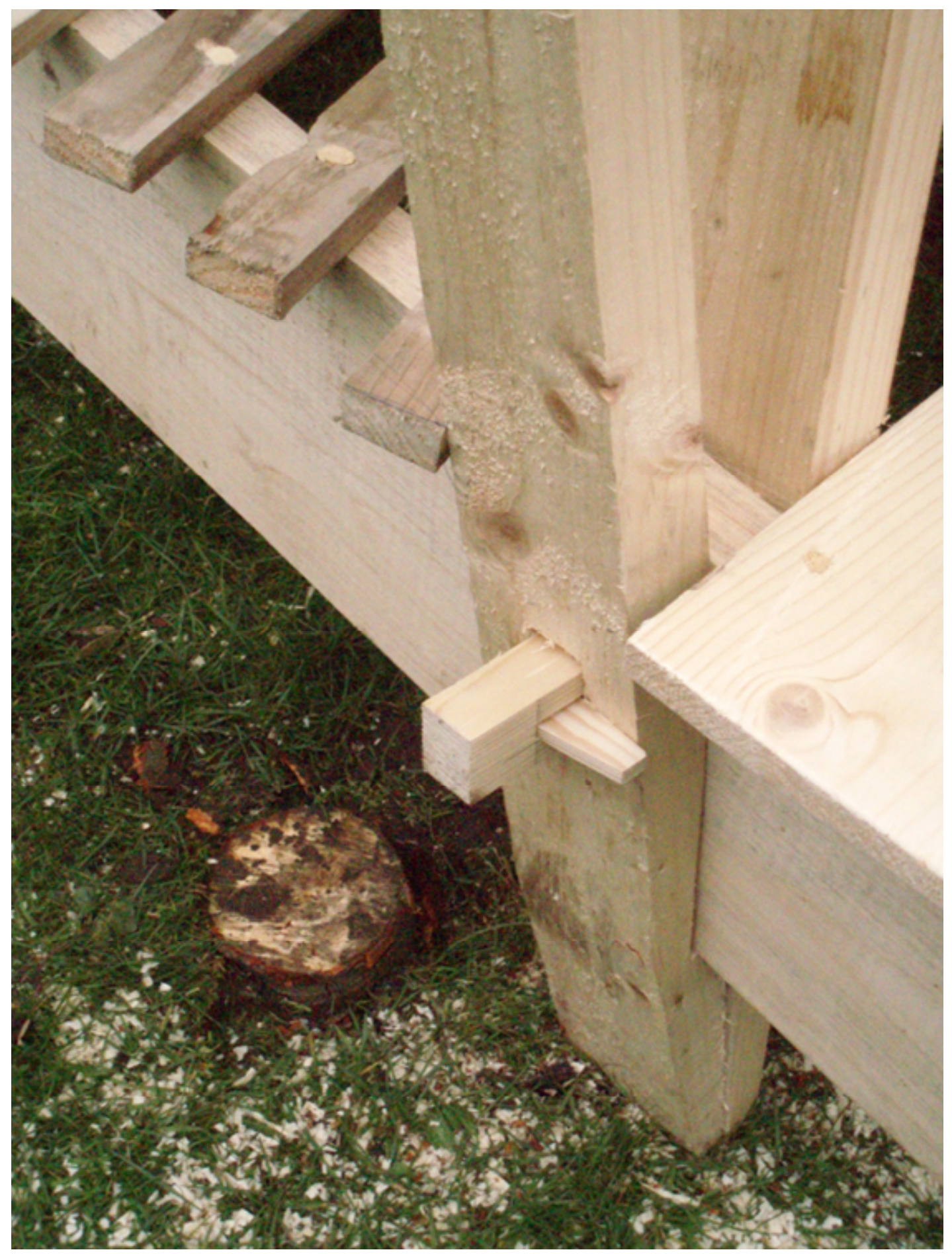

Image 4: Irish Timber \& Sustainability 2007, Design | Build Team: Sorcha O'Higgins, Neal Patterson, Cormac Fahey, Neil Gleeson, Finn Christiansen, Tim Varian, Patrick White, Hugh Dolan, Brian Guckian 


\section{Conclusions}

When a poet's mind is perfectly equipped for his work, it is constantly amalgamating disparate experiences; the ordinary man's experience is chaotic, irregular, fragmentary. The latter falls in love, or reads Spinoza, and these two experiences have nothing to do with each other, or with the noise of the typewriter or the smell of cooking; in the mind of the poet these experiences are always forming new wholes.

\section{T.S.Eliot, Metaphysical Poets}

As a student of architecture I was told that architects were poets, thus were born into, rather than trained for, their profession. Though initially unconvinced experience has shed light on the implied meaning of such a statement. It is in the constant amalgamation of disparate experiences into new wholes that the practitioner of architecture shares an alliance to the poet. But like a poet one must be educated in the traditions of one's craft, as Eliot argues elsewhere.

The transfer and appropriation of diverse fields of knowledge within the discipline of architecture is essential to the meaningful practice of the craft. But to be truly valuable it is essential that a synthesis occur between the practicalities of building and the insights of experience and knowledge from other traditions. A synthesis possible by understanding the complex network of relationships that underpin materials and their use within society, best achieved through a tactile engagement, which enlivens our traditional intellectual training.

\section{References}

Allen, Stan. Practice: Architecture, Technique and Representation. London: Routledge, 2000.

Eliot, T.S. "Metaphysical Poets." First published in the Times Literary Supplement 20 Oct. 1921,

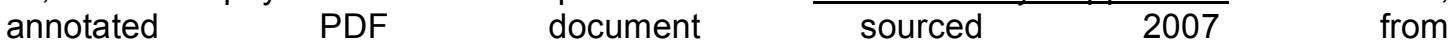
http://virtual.clemson.edu/groups/dial/T\&Vseminar/tecritearly.html.

Lui, A, Macdonald, C, Shotton, E, Techentin, W. "Weather Register." Journal of Architectural Education. ACSA 53/2 (November 1999): 110-114.

Lloyd Thomas, Katie, ed. Material Matters: Architecture and Material Practice. Oxon: Routledge, 2007.

Parkinson, Eric. "Practical Modelling And Hypothesis Testing In Primary Design And Technology Education." International Journal of Technical Design Education. Netherlands: Kluwer Academic Publishers, 2006. Accessed through Springer Science \& Business Media 2007.

Poole, Scott. "Pumping Up: Digital Steroids and the Design Studio." Lloyd Thomas, ed. Material Matters: Architecture and Material Practice. Oxon: Routledge, 2007.

Salter, Peter. "Notes Towards a Technical Study." TS: Intuition \& Process, Themes VI. London: Architectural Association, 1989.

Shotton, Elizabeth, "Technical Intuition: Experimenting with the Role of Reason and Intuition in the Design Process." Voyatzaki, M. ed. Visions for the Future of Construction Education, Transactions on Architectural Education No. 22. Greece: European Association For Architectural Education, 2004: 158-165.

Vitruvius Pollio. Book 1, Chapter I: The Education Of The Architect, The Ten Books On Architecture. Morgan, ed., 2007, http://www.perseus.tufts.edu/cgibin/ptext?doc=Perseus\%3Atext\%3A1999.02.0073;query=cha pter\%3D\%232;layout=;1oc=1 . preface $\% 201$ 